\title{
ĐÁNH GIÁ KẾT QUẢ PHẪU THUẬT NộI SOI CHỨC NĂNG MŨI XOANG (FESS) CÓ SỬ DỰG DAO HÀN MẠCH PLASMA
}

\section{TÓM TẮT}

Mục tiêu: đánh giá kết quả phẫu thuật nội soi chức năng mũi xoang có sứ dụng dao hàn mạch Plasma Aquamantys trong điều trị bệnh lý viêm mũi xoang mạn tính. Phương pháp nghiên cứu: mô tả tiến cứu có can thiệp. Địa điểm nghiên cứu: Bệnh viện Đai hoc Y Hà Nôi. Bênh nhân: 26 bệnh nhẩn được phẫu thuật nội soi chức năng mũi xoang mở một xoang từ $8 / 2020$ đến $8 / 2021$. Kết quả: giảm lương máu mất trong phẫu thuật $(38,85 \pm 14,79 \mathrm{ml})$, giảm thời gian phẫu thuât $(53,08 \pm 1,92$ phút), tao phẫu trường tốt (Boezaart $=1,33 \pm 0,14)$, không tai biến biến chứng, không đặt merocel sau phấu thuât, $100 \%$ thở được bằng mũi bên phẫu thuật sau phẫu thuật 2448h, các triêuu chứng của bệnh sau 3 tháng tiến triển tốt. Kết luận: phâuu thuật nội soi chức năng mũi xoang có cẩm máu bằng dao Plasma Aquamantys trong điêu trị viêm mũi xoang mạn tính: an toàn, sau phẫu thuât 24-48h và sau 3 tháng đều đat kết quả tốt.

Từ khóa: phẫu thuật nội soi chức năng mũi xoang (FESS), viêm mũi xoang mạn tính, thiết bị hàn mạch Plasma Aquamantys.

\section{SUMMARY \\ OUTCOME ASSESSMENT OF FUNCTIONAL ENDOSCOPIC SINUS SURGERY (FESS) WITH PLASMABLADE}

Objective: To evaluate the functional endoscopic sinus surgery using Plasma Aquamantys bipolar sealer for chronic rhinosinusitis. Methods: cross - sectional descriptive study. Research location: Ha Noi Medical University Hospital. Patients: 26 patients had functional endoscopic procedure one sinus surgery from August 2020 to August 2021. Results:reduced blood loss intraoperative $(38,85 \pm 14,79 \mathrm{ml})$, reduced timing of surgery $(53,08 \pm 1,92$ minutes $)$,good visualization of surgical field (Boezaart $=1,33 \pm 0,14$ ), no complications, no using merocel nasal packing, $100 \%$ patients could breath through their operatived nose in 24-48h postoperative, improved the symptoms after surgery 3 months .Conclusions: the functional endoscopic sinus surgery using Plasma Aquamantys bipolar sealer for chronic rhinosinusitis: safety, good results in 24-48h postoperative and 3 months after surgery.

Keywords: functional endoscopic sinus surgery (FESS), chronic rhinosinusitis, Plasma Aquamantys bipolar sealer.

\section{Trương Đại học Y Hà Nội}

Bênh viên Đai hoc Y Hà Nôi

Chịu trách nhiệm chính: Phạm Quang Tuyến

Email: drtuyen92@gmail.com

Ngày nhận bài: 8.6.2021

Ngày phản biên khoa hoc: 30.7.2021

Ngày duyệt bài: 9.8.2021

\section{Phạm Quang Tuyến ${ }^{1}$, Cao Minh Thành ${ }^{1,2}$ \\ I. ĐĂT VẤN ĐỀ}

Viêm mũi xoang mạn tính là tình trạng viêm niêm mạc mũi và các xoang cạnh mũi từ 12 tuần trở lên, bệnh có thể gặp ở cả người lớn và trẻ em. Điều tri bệnh gồm hai phương pháp nội khoa và phẫu thuât. Phẫu thuâtt được chỉ định khi giải quyết nguyên nhân bệnh hoặc điều trị nội khoa thất bại, trong đó phẫu thuật nội soi chức năng mũi xoang là lựa chọn hàng đầu do tiêu chí của phẫu thuật là phục hồi sớm sinh lý niêm mạc mũi xoang sau mổ mà vẫn đảm bảo lấy trọn bệnh tích [1]. Tuy nhiên việc sử dụng các dụng cụ truyền thống khiến cầm máu trong quá trình phẫu thuật còn hạn chế. Hệ thống Plasma Aquamantys của Medtronic với công nghệ Transcollation ra đời hiện là tối ưu cầm máu trong phẫu thuật của một số chuyên ngành: thần kinh cột sống, ung bướu, chỉnh hình nhưng lại chưa được ứng dụng trong phẫu thuật nội soi mũi xoang tại Việt Nam [2]. Vì vậy nghiên cứu này được thực hiệnvới mục tiêu chính: "Đánh giá kêt quả phẫu thuật nội soi chức năng mũi xoang có sử dung dao hàn mach Plasma Aquamantys trong điều trị bệnh lý viêm mũi xoang mạn tính".

II. ĐỐI TƯợNG VÀ PHƯƠNG PHÁP NGHIÊN CỨU

\section{1 Đối tượng nghiên cứu}

- Bênh nhân được chẩn đoán viêm mũi xoang mạn tính điêuu trị tại Bệnh viện Đại học Y Hà Nội từ $8 / 2020$ đến $8 / 2021$

- Số lượng bệnh nhân: 26

2.1.1 Tiêu chuẩn lựa chọn: - Tuổi >16

- Trước mổ có chụp phim cắt lớp vi tính mũi xoang tiêu chuẩn tư thế Coronal, Axial dựng hình Sagital.

- Được phẫu thuật nội soi mở một xoang, trong phẫu thuật sử dụng thiết bị hàn mạch Plasma Aquamantys.

- Đánh giá sau phẫu thuâtt trong vòng 24-48h

- Đánh giá lại sau phẫu thuật 3 tháng

- Bệnh nhân và gia đình đồng ý nghiên cứu

\subsubsection{Tiêu chuấn loại trù}

- Bệnh nhân đã phẫu thuật nội soi mũi xoang trước đó

Bệnh nhân không được sử dụng hoặc không đồng ý sử dụng thiết bị Plasma Aquamantys trong phẫu thuật

- Bệnh nhân không đồng ý tham gia nghiên cứu

2.3 Phương pháp nghiên cứu 


\subsubsection{Thiêt kếnghiên cứu}

- Nghiên cứu mô tả tiến cứu có can thiệp

2.1.2 Phương tiện nghiên cứu

- Bênh án nghiên cứu theo mấu

- Trang thiết bị khám, phẫu thuật nội soi gồm: bộ nội soi Karl- Storz, camera, dây dẫn sáng và optic $4 \mathrm{~mm} 0$ độ, 45 độ, bộ dụng cụ phẫu thuật nội soi mũi xoang.

- Hệ thống AEX Generator, tay Plasma, tay Aquamantys

- Phim CLVT mũi xoang trước mổ

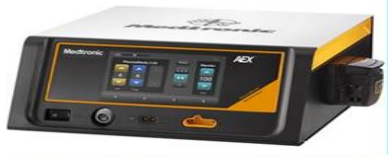

78.

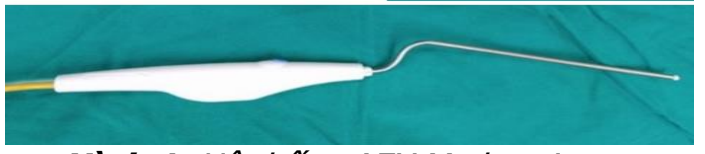

Hình 1. Hệ thống AEX Medtronic, tay Aquamantys

2.1.3 Xử lý số liệu. Số liệu được phân tích bằng thuật toán thống kê mô tả, sử dụng phần mềm SPSS 20.0

\section{KẾT QUẢ NGHIÊN CỨU}

\section{1 Đặc điểm chung}

- Tuổi nhỏ nhất là 31 , lớn nhất là 74 , nhóm tuổi hay gặp nhất từ 46-55(38,5\%), độ tuổi từ 26-55 có $20 / 26$ bệnh nhân chiếm $76,9 \%$, tuổi trung bình là 48,46 $\pm 9,87$

- Giới: tỷ lệ nam: nữ = 10:16

- Thời gian diê̂n biến của bệnh chủ yếu từ 1-3 năm $(38,5 \%)$, thời gian diễn biến dưới 6 tháng có $19,2 \%$

\section{2 Đặc điểm lâm sàng và cận lâm sàng}

3.2.1 Triệu chứng cơ năng

Bảng 1. Triệu chứng cơ năng của bệnh nhân khi vào viện $(\mathrm{N}=\mathbf{2 6})$

Triệu chứng cơ năng Ngạt tắc mũi

\begin{tabular}{|c|c|}
\hline $\mathbf{n}$ & \% \\
\hline 22 & 84,6 \\
\hline
\end{tabular}

\begin{tabular}{|c|c|c|}
\hline Chảy dịch mũi & 21 & 80,8 \\
\hline Giảm ngứi & 13 & 50 \\
\hline Ngửi thấy mưii hôi thối & 3 & 11,5 \\
\hline Đau nhức mặt & 13 & 50 \\
\hline Đau đầu & 12 & 46,2 \\
\hline Dấu hiệu mắt & 1 & 3,8 \\
\hline
\end{tabular}

Nhận xét: Triệu chứngcơ năng hay gặp nhất là ngạt tắc mũi $(84,6 \%)$ và chảy dịch mũi sau $(80,8 \%)$. Tiếp theo là đau nhức mặt $(50 \%)$ và giảm ngửi (50\%), đau đầu (46,2\%). Triệu chứng ít gặp là ngửi thấy mùi hôi thối $(11,5 \%)$ và dấu hiệu mắt $(3,8 \%)$.

\subsubsection{Triệu chứng thực thê}

Bảng 2. Đặc điểm hình ảnh nội soi $(N=26)$

\begin{tabular}{|c|c|c|}
\hline Triệu chứng thực thế & $\mathbf{n}$ & $\mathbf{\%}$ \\
\hline Polyp & 5 & 19,2 \\
\hline Phù nề niêm mạc & 21 & 80,8 \\
\hline Chảy dịch mủ & 22 & 84,6 \\
\hline Tố chức ngờ nấm & 2 & 7,7 \\
\hline Không phát hiện bất thường & 4 & 15,4 \\
\hline
\end{tabular}

Nhân xét: Tình trạng chảy dịch mủ $(84,62 \%)$ và phù nề niêm mạc mũi $(80,8 \%)$ xuất hiện nhiều nhất. Có polyp mũi chiếm $19,2 \%$ và $7,7 \%$ thấy có tổ chức ngờ nấm. Trên nội soi không phát hiện bất thường có 15,4\%.

\subsubsection{Triệu chứng cân lâm sàng}

Bảng 3. Đặc điểm trên phim chụp CLVT $(N=26)$

\begin{tabular}{|c|c|c|}
\hline Đặc điếm tốn thương & $\mathbf{n}$ & $\mathbf{\%}$ \\
\hline Mờ một phần xoang hàm & 2 & 7,7 \\
\hline Mờ toàn bộ xoang hàm & 23 & 88,5 \\
\hline Mờ xoang hàm + sàng trước & 10 & 38,5 \\
\hline Mờ xoang bướm & 1 & 3,8 \\
\hline Điếm Lund Mackay & \multicolumn{2}{|c|}{$3,85 \pm 0,97$} \\
\hline
\end{tabular}

Nhân xét: Tốn thương mờ toàn bộ xoang hàm là chủ yếu $(88,5 \%)$, mờ xoang hàm + sàng trước kèm theo có 38,5\%. Một trường hợp mờ xoang bướm. Điểm Lund Mackay trung bình là $3,85 \pm 0,97$.

\section{3 Đặc điểm phẫu thuật}

Bảng 4. Đặc điểm phẫu thuật $(N=26)$

\begin{tabular}{|c|c|c|c|c|c|c|}
\hline \multirow{2}{*}{ Đặc điểm trong phẫu thuật } & \multicolumn{2}{|c|}{ Do nấm } & \multicolumn{2}{|c|}{ Nhiềm khuấn } & \multicolumn{2}{|c|}{ U nhầy } \\
\hline & $\mathbf{n}$ & $\%$ & $\mathbf{n}$ & $\%$ & $\mathbf{n}$ & $\%$ \\
\hline Phâu thuật xoang hàm & 17 & 65,4 & 8 & 30,8 & 0 & 0 \\
\hline Phâuu thuật xoang bướm & 0 & 0 & 0 & 0 & 1 & 3,8 \\
\hline Đặt merocel cầm máu sau phâu thuật & 0 & 0 & 0 & 0 & 0 & 0 \\
\hline Tai biến phâu thuật & 0 & 0 & 0 & 0 & 0 & 0 \\
\hline Điếm Boezaart & \multicolumn{6}{|c|}{$1,33 \pm 0,14$} \\
\hline Thời gian phâu thuật (phút) & \multicolumn{6}{|c|}{$53,08 \pm 1,92$} \\
\hline Lượng máu mất trong phâu thuật (ml) & \multicolumn{6}{|c|}{$38,85 \pm 14,79$} \\
\hline
\end{tabular}

Nhận xét: Trong nghiên cứu phẫu thuật mở xoang hàm là chủ yếu $(96,2 \%)$, có một ca mở xoang bướm. Nguyên nhân do nấm chiếm
$65,4 \%$, do nhiễm khuẩn chiếm $30,8 \%$ và do u nhây chiếm $3,8 \%$. Không trường hợp nào bị tai biến phẫu thuật, không đặt merocel cầm máu 
sau phẫu thuật. Điểm Boezaart đánh giá phẫu trường dựa trền mức độ chảy máu, trung bình là $1,33 \pm 0,14$. Thời gian phẫu thuật tính từ lúc bắt đầu gây tê đến kết thúc phẫu thuật, trung bình là $53,08 \pm 1,92$ phút. Lượng máu mất trung bình là $38,85 \pm 14,79 \mathrm{ml}$.

\subsection{Sau phẫu thuật 24-48h}

Bảng 5. Đặc điềm lâm sàng sau phẫu thuật $(N=26)$

\begin{tabular}{|c|c|c|c|}
\hline Triệu chứng & $\mathbf{n}$ & $\mathbf{\%}$ & VAS \\
\hline Ngạt mũi & 11 & 42,3 & \\
\hline Khồ họng & 0 & 0 & \\
\hline Ho & 0 & 0 & \\
\hline Đau vùng phâu thuật & 26 & 100 & $3,61 \pm 0,57$ \\
\hline Đau vùng mặt & 17 & 65,4 & $3,53 \pm 1,01$ \\
\hline Đau đâuu & 12 & 46,2 & $4,5 \pm 1,38$ \\
\hline
\end{tabular}

Nhân xét: Triêu chứng găp ở tất cả các bênh nhân là đau vùng phấu thuật với điểm VAS = $3,61 \pm 0,57$. Có $17 / 26$ bệnh nhẩn đau vùng mặt với điểm VAS $=3,53 \pm 1,01$ và $12 / 26$ bệnh nhân đau đầu với điểm VAS $=4,5 \pm 1,38$. Chỉ có $42,3 \%$ bệnh nhân thây ngạt mũi sau phẫu thuật và không có bệnh nhân nào ho, khô họng sau phẫu thuật.

Bảng 6. Kêt quả đoo gương Glatzel bên phẫu thuật sau phẫu thuật 24-48h ( $N=26)$

\begin{tabular}{|c|c|c|}
\hline Mức độ ngạt & $\mathbf{n}$ & $\mathbf{\%}$ \\
\hline Nạang $(<3 \mathrm{~cm})$ & 1 & 3,8 \\
\hline Vữa $(3-4 \mathrm{~cm})$ & 11 & 42,3 \\
\hline Nhẹ $(4-6 \mathrm{~cm})$ & 7 & 26,9 \\
\hline Không ngạt $(>6 \mathrm{~cm})$ & 7 & 26,9 \\
\hline
\end{tabular}

Nhận xét: Sau phâuu thuật 24-48h có $100 \%$ bệnh nhân thở được bằng mũi bên phẫu thuật, tỉ lệ ngạt nặng chỉ 3,8\%, tỉ lệ ngạt nhè 26,9\%, tỉ lệ không ngạt $26,9 \%$ và tỉ lệ ngạt vừa là $42,3 \%$.

\subsection{Sau phẫu thuật 3 tháng}

Bảng 7. Đặc điểm lâm sàng sau phẫu thuật 3 tháng $(N=26)$

\begin{tabular}{|c|c|c|c|c|}
\hline & $\begin{array}{c}\text { Trước phâuu } \\
\text { thuật }\end{array}$ & \multicolumn{2}{|c|}{$\begin{array}{c}\text { Sau phâau } \\
\text { thuật }\end{array}$} \\
\hline Triệu chứng & $\mathbf{n}$ & $\mathbf{\%}$ & $\mathbf{n}$ & $\mathbf{\%}$ \\
\hline Ngặ mũi & 22 & 84,6 & 2 & 7,7 \\
\hline Chày mũi & 21 & 80,8 & 4 & 15,4 \\
\hline Giảm ngữi & 13 & 50 & 2 & 7,7 \\
\hline Đau nhức mặt & 13 & 50 & 0 & 0 \\
\hline $\begin{array}{c}\text { Nội soi bình } \\
\text { thường }\end{array}$ & 4 & 15,4 & 24 & 92,3 \\
\hline Nội soi có polyp & 5 & 19,2 & 0 & 0 \\
\hline $\begin{array}{c}\text { Nội soi phù nề } \\
\text { niêm mạc }\end{array}$ & 21 & 80,8 & 2 & 7,7 \\
\hline $\begin{array}{c}\text { Nội soi chảy dịch } \\
\text { nhâyy hoặc mủ }\end{array}$ & 22 & 84,6 & 0 & 0 \\
\hline Nội soi có sẹo dính & 0 & 0 & 0 & 0 \\
\hline
\end{tabular}

Nhận xét: Sau phẫu thuật 3 tháng, chỉ còn $7,7 \%$ bệnh nhân có cảm giác ngạt mũi, $15,4 \%$ bệnh nhân có cảm giác chảy mũi, $7,7 \%$ bệnh nhân thấy giảm ngửi và không còn trường hợp nào đau nhức mặt.

Triệu chứng thực thể trên hình ảnh nôi soi có $92,3 \%$ trường hợp thây bình thường, $7,7 \%$ có phù nề niêm mạc hốc mổ, không có trường hợp nào có chảy dịch nhây mủ hay có sẹo dính, polyp tái phát.
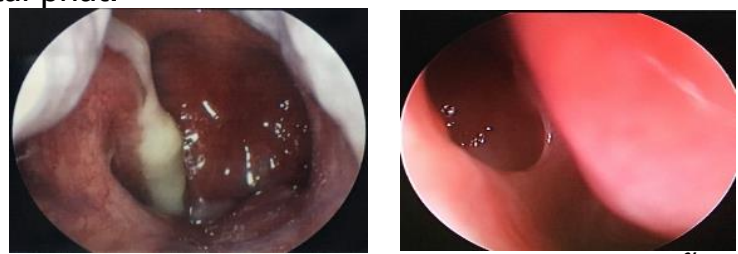

Hình 2. Hinh ảnh nội soi trước và sau phẫu thuật nội soi chức năng mũi xoang có dùng dao Plasma Aquamantys 3 tháng (Bệnh nhân Dương Quyêt C mã hồ sơ 2104020992 phẫu thuật ngày 14/4/2021).

\section{BÀN LUẬN}

\section{1 Đặc điểm chung}

- Tuổi nhỏ nhất là 31, tuổi cao nhất là 74, hay gặp nhất ở nhóm tuổi 46-55 (38,5\%), giới nam: nữ $=1: 1,6$. Kết quả này phù hợp với nghiên cứu của Lê Hải Nam [3]. Độ tuổi tử 26-55 có 20/26 bệnh nhân chiếm $76,9 \%$ lần nữa khẳng định ảnh hưởng của viêm mũi xoang mạn tính tới học tập, lao động nên họ tới khám và điều trị nhiề.Trong hầu hết các nghiên cứu trong và ngoài nước cũng không nêu lên sự khác nhau về giới.

- Thời gian diễn biến của bệnh chủ yếu từ 1-3 năm $(38,5 \%)$, thời gian diễn biến dưới 6 tháng có $19,2 \%$, kết quả này thấp hơn nghiên cứu của Lê Hải Nam [3] với thời gian mắc bệnh chủ yếu là trên 5 năm, trung bình $5,1 \pm 3,2$ năm cho thấy nhận thức, quan tâm tới sức khỏe của bệnh nhẩn trong nghiên cứu có tăng lên.

\section{2 Đặc điểm lâm sàng và cận lâm sàng} trước phẩu thuật

- Triệu chứng cơ năng hay gặp nhất trong nghiên cứu là ngạt mũi một bên chiếm $84,6 \%$ và chảy dịch mũi cùng bên ngạt chiếm $80,8 \%$. Kết quả tương tự nghiên cứu của Phạm Trung Kiên [4]. Triệu chứng ngạt mũi thường từ từ tăng dần một bên, lúc đâu ngạt ít, từng lúc, sau thường xuyên hơn, có trường hợp dẫn đến ngạt hoàn toàn, kèm theo ngạt mũi là chảy mũi mủ. Tính chất mủ tùy thuộc vào nguyên nhân gây viêm mũi xoang. Ngửi thấy mùi hôi thối chiếm $11,5 \%$, dấu hiệu mắt chiếm $3,8 \%$ tuy là triệu chứng ít gặp nhưng mùi hôi thối khiến bệnh nhân khó chịu nhiều, dấu hiệu mắt là một trong những dấu hiệu cảnh báo nguy hiểm của viêm mũi xoang, 
do đó bệnh nhân sẽ đến viện sớm hơn. Triệu chứng đau nhức mặt chiếm $50 \%$, đau đầu chiếm $46,2 \%$ và giảm ngửi chiếm $50 \%$. Nguyên nhân đau nhức mặt do bít tắc phức hợp lố ngách gây tăng áp lực lòng xoang, thường đau nhức mặt có đau đầu kèm theo. Triệu chứng đau nhức mặt, đau đâu, giảm ngứi tiến triển âm ỉ, ít ảnh hưởng đến sinh hoạt, lao động của bệnh nhân và dễ bị chẩn đoán nhầm với các bệnh lý khác nên bệnh nhân thường đến viện sau khi đã điều trị một thời gian dài.

- Triệu chứng thực thể gặp nhiều nhất trên nội soi là chảy dịch mủ $(84,6 \%)$ và phù nề niêm mạc mũi $(80,8 \%)$ trong đó toàn bộ là chảy dịch mủ khe giữa do trong nghiên cứu có $25 / 26$ trường hợp tổn thương xoang hàm. Tỷ lệ này tương tự nghiên cứu của Phạm Trung Kiên [4]. Có 5 trường hợp chúng tôi không thấy phù nề niêm mạc gồm 4 trường hợp viêm mũi xoang do nấm và 1 trường hợp u nhầy xoang bướm. Trong nghiên cứu tất cả polyp mũi xuất hiện trong viêm mũi xoang mạn tính nhiễm khuẩn $(19,2 \%)$, polyp mũi là hình thái thường gặp của viêm mũi xoang mạn tính. Có $2 / 26(7,7 \%)$ trường hợp trên nội soi quan sát thấy khối đen bẩn trong lòng xoang nghi ngờ nấm, đây là dấu hiệu rất có giá trị trong chẩn đoán viêm mũi xoang do nấm.

- Triệu chứng trên phim cắt lớp vi tính có mờ toàn bộ xoang hàm là chủ yếu $(88,5 \%)$, mờ xoang hàm hai bên chỉ chiếm $7,7 \%$, tî lệ này tương tự nghiên cứu của Lê Đức Đông [5], mờ xoang hàm thường kèm theo mờ phức hợp lỗ ngách, có $38,5 \%$ mờ cả xoang hàm và xoang sàng, tuy nhiên chúng tôi đánh giá mờ xoang sàng trước là do ứ đọng dịch do phức hợp lổ ngách bi bít tắc nên trong phẫu thuật không can thiệp vào hệ thống sàng trước. Điểm Lund Mackay trung bình là $3,85 \pm 0,97$ tương đồng với nghiên cứu của Jae Yong Lee [6]. Như vậy phim CLVT giúp gợi ý các xoang tổn thương và đánh giá mức độ tổn thương, mức độ lan rộng.

\section{3 Đặc điểm phầu thuật}

- Trong nghiên cứu phẫu thuật mở xoang hàm là chủ yếu $(96,2 \%)$, nguyên nhân do nấm chiếm $65,4 \%$, nguyên nhân do nhiễm khuẩn chiếm $30,8 \%$, có một ca mở xoang bướm do u nhầy $(3,8 \%)$, thời gian phẫu thuật trung bình là $53,08 \pm 1,92$ phút, khi so sánh với nghiên cứu của Andrew J Thomas [7] có thời gian phẫu thuật trung bình vào nhóm xoang trước là 58 phút thấy sự khác biệt có ý nghĩa $(p=0,017)$. Lượng máu mất trong phẫu thuật là $38,85 \pm 14,79(\mathrm{ml})$, điểm Boezaart là $1,33 \pm 0,14$, khi so sánh với nghiên cứu của Suneeta Gollapudy [8] có lượng máu mất trong phẫu thuật là $50(\mathrm{ml})$, điểm Boezaart là 2 thấy sự khác biệt có ý nghĩa $(p<0,05)$. Thời gian phẫu thuật, kĩ thuật cầm máu còn phụ thuộc vào kinh nghiệm của phẫu thuật viên, tựy nhiên chúng tôi thấy sự cải thiện thời gian phẫu thuật, giảm lượng máu mất một phần do thiết bị hiệu quả làm giảm thời giạn thao tác cầm máu trong phẫu thuật và tạo phẫu trường tốt hạn chế tai biến phẫu thuật. Điều đó còn thể hiện trong nghiên cứu $100 \%$ không có tai biến phẫu thuật và không phải đặt merocel sau phẫu thuật. Không đặt merocel sau phẫu thuật làm giảm đáng kể mức độ khó chịu cho bệnh nhân ngay sau phẫu thuật và giảm thời gian nằm viện.

\subsection{Sau phẫu thuâat}

- Triệu chứng gặp ở tất cả các bệnh nhân là đau vùng phẫu thuật với điểm VAS $=3,61 \pm 0,57$, đây là mức độ nhẹ, sau 24 tiếng không bệnh nhân nào phải dùng đến thuốc giảm đau. Có 17/26 bệnh nhân đau vùng mặt với điểm VAS = $3,53 \pm 1,01$ kết quả này tương tự nghiên cứu của Nguyễn Phi Long [9]. Đau đầu có 12/26 bệnh nhân với điểm VAS $=4,5 \pm 1,38$, tất cả đều là đau đầu đã xuất hiện trước mổ, sau mổ triệu chứng chưa giảm ngay.

- Chỉ 42,3\% bệnh nhân cảm thây ngat mũi sau phẫu thuật, tuy nhiên đây là triệu chứng chủ quan của người bệnh, khi kiểm chứng lại bằng gương Glatzel thấy sau phẫu thuâat tất cả bệnh nhân đều thở được bên mũi phẩu thuật, tî̉ lệ ngạt nặng chỉ có $3,8 \%$, tỉ lệ ngạt nhe $26,9 \%$, tì lệ không ngạt $26,9 \%$, tỉ lệ ngạt vừa $42,3 \%$. Kết quả này là cải thiện đáng kể so với phẫu thuật có đặt merocel. Trong phẩu thuật có đặt merocel bệnh nhân không thể thở được mũi bên phẫu thuật do vật liệu cầm máu che lấp toàn bộ khe thở làm cho bệnh nhân phải thở miệng, từ đó dẫn tới ho, khô họng sau phẫu thuật. Trong nghiên cứu chúng tối không thấy bệnh nhân nào ho, khô họng mới xuất hiện sau phấu thuật.

\subsection{Sau phẫu thuật 3 tháng}

- Tất cả các bệnh nhân của chúng tôi được khai thác và đánh giá triệu chứng cơ năng sau phẫu thuật 3 tháng. Kết quả cho thây chỉ còn $7,7 \%$ bệnh nhân có cảm giác ngạt mũi, $15,4 \%$ bệnh nhân có cảm giác chảy mũi, $7,7 \%$ bệnh nhân thấy giảm ngửi và không còn trường hợp nào đau nhức mặt, kết quả này tương tự nghiên cứu của Lê Đức Đông [5].

- Triệu chứng thực thể qua nội soi sau 3 tháng thấy có tới $92,3 \%$ hình ảnh bình thường, lỗ thông xoang mở rộng, niêm mạc không phù nề, không chảy dịch, không có vảy hay sẹo dính, 
chỉ có $7,7 \%$ trường hợp còn nề nhe niêm mạc, tỉ lệ này cao hơn trong nghiên cứu của Lê Đức Đông [5] có $82,1 \%$ hốc mũi bình thường, $7,7 \%$ có sẹo dính, 5,1\% tái phát polyp và $5,1 \%$ niêm mạc phù nề. Như vậy kết quả phẫu thuật đạt được là tốt hơn.

\section{KẾT LUÂ̂N}

Phẫu thuật nội soi chức năng mũi xoang có cầm máu bằng dao Plasma Aquamantys trong điều trị viêm mũi xoang mạn tính: an toàn (không có tai biến phẫu thuật và biến chứng hậu phẫu), tạo phẫu trường tốt (Boezaart = $1,33 \pm 0,14)$, làm giảm lượng máu mất trong mổ (lượng máu mất $=38,85 \pm 14,79 \mathrm{ml}$ ) giảm thời gian phẫu thuật (thời gian trung bình $53,08 \pm 1,92$ phút), không đặt merocel cầm máu sau phẫu thuật, tất cả bệnh nhân đều thở được bằng mũi bên phẫu thuật sau phẫu thuật 2448h, giảm các triệu chứng khó chịu do đặt merocel, kết quả tốt sau phẫu thuật 3 tháng.

\section{TÀI LIÊU THAM KHẢO}

1. Fokkens WJ, Lund VJ, Hopkins $C_{\text {, }}$ et al, European Position Paper on Rhinosinusitis and Nasal Polyps 2020. Rhinology. 2020;58(Suppl S29):1-464.

2. Medtronic. Electrosurgical Products - Aquamantys BipolarSealers.www.medtronic.com/products/AEXg enerator [online],Available at, Accessed. 2009.

3. Lê Hải Nam, Võ Thanh Quang (2020). Đăc điểm lâm sàng trong viêm mũi xoang mạn tính ở người lớn tại Bệnh viện Tai Mũi Họng Trüng ương năm 2019. Tap chí khoa học Đai học Quốc Gia Hà Nội, số 36, tập 2 tr43-49

4. Phạm Trung Kiên (2019). Nghiên cứu đăc điểm lâm sàng, cắt lớp vi tính, mô bệnh học các tổn thương xoang một bên. Luận văn chuyên khoa cấp II, Trường đại học Y Hà Nội. tr51,65.

5. Lế Đức Đông (2019). Nghiên cứu đặc điểm lâm sàng, cân lâm sàng và đánh giá kết quả điều trị phẫu thuật của viêm mũi xoang do nấm. Luânn văn chuyên khioa cấp II, Trường đại học Y Hà Nôii.tr78.

6. Yong Lee, Jae. (2008). Unilateral paranasal sinus diseases: analysis of the clinical characteristics, diagnosis, pathology, and computed tomography findings. Acta Oto-Laryngologica, 128(6), 621-626.

7. Thomas AJ, Smith KA, Newberry CI, Cardon B, Davis B, Ou Z, Presson AP, Meier JD, Alt JA. Operative time and cost variability for functional endoscopic sinus surgery. Int Forum Allergy Rhinol. 2019 Jan;9(1):23-29.

8. Gollapudy S, Gashkoff DA, Poetker DM, Loehrl TA, Riess ML. Surgical Field Visualization during Functional Endoscopic Sinus Surgery: Comparison of Propofol- vs Desflurane-Based Anesthesia. Otolaryngol Head Neck Surg. 2020 Oct;163(4):835-842.

9. Nguyễn Phi Long, Đỗ Lan Hương (2018). Kết quả bước đầu cải tiến một số kĩ thuật cầm máu trong phấu thuật nội soi mũi xoang. Tạp chí y dược học quân sự, số 9

\section{KẾT QUẢ HÓA TRỊ PHÁC ĐỒ R-CHOP BỆNH U LYMPHO KHÔNG HODGKIN TẾ BÀO B LỚN LAN TỎA}

\section{TÓM TẮT}

Mục tiêu: Đánh giá kết quả điều trị phác đồ RCHOP bệnh u lympho ác tính không Hodgkin tế bào $B$ lớn lan tỏa. Đối tượng và phương pháp nghiên cứu: Nghiên cứu mô tả hồi cứu trên 35 bệnh nhân được điều tri phác đồ R-CHOP tai bênh viên Đ̇ai hoc Y Hà Nôi từ tháng 01/2015 đến tháng 06/2021. Kết quả: Đặc điểm lâm sàng, cận lâm sàng: Tuổi trung bình là $57 \pm 13,7$, nam/nữ $=1,2: 1$. Phần lớn $(94,3 \%)$ có toàn trạng tốt. Sờ thây hạch ngoại vi là triệu chứng thường gặp nhất (40\%). Khoảng $1 / 3$ bệnh nhân có tổn thương ngoài hạch (34,3\%). 65,7\% bệnh nhân tăng LDH trước điêuu trị. Kêt quá điều trị và độc tính của phác đồ: Tỉ lệ đạt ứng hoàn toàn sau 3 chu kì là

${ }^{1}$ Trường Đại học Y Hà Nọi,

²Bênh viên Đai hoc Y Hà Nôi

Chịu trách nhiệm chính: Trịnh Lê Huy

Email: trinhlehuy@hmu.edu.vn

Ngày nhận bài: 4.6.2021

Ngày phản biên khoa hoc: 31.7.2021

Ngày duyệt bài: 10.8.2021

\section{Phạm Duy Mạnh1, Trịnh Lê Huy 1,2}

$28,6 \%$, sau 6 chu kì là 82,9\%. Tỉ lệ bệnh nhân chưa tiến triển tại trung vị theo dõi 3 nẳm sau điều trị là $87,8 \%$. Hạ bạch cầu hạt là độc tính thường gặp nhất $(42,9 \%)$, chỉ có $5,8 \%$ gặp hạ bạch cầu độ 3,4 . Các độc tính còn lại ít gặp, chủ yếu độ 1 và độ 2 . Kết luận: Phác đồ R-CHOP đem lại hiệu quả cao trong khi an toàn và dung nạp tốt.

Tư khóa: U lympho ác tính không Hodgkin, tế bào $\mathrm{B}$ lớn lan tỏa, R-CHOP

\section{SUMMARY}

\section{RESULTS OF R-CHOP THERAPY IN DIFFUSE} LARGE B-CELL NON-HODGKIN LYMPHOMA

Objectives: To evaluate the treatment results of R-CHOP therapy in diffuse large B-cell non-hodgkin lymphoma. Patients and Methods: Descriptive, retrospective study on 35 patients treated with RCHOP therapy at Hanoi Medical University Hospital from January 2015 to June 2021. Results: Clinicopathologic characteristics: Mean age was $57 \pm 13.7$, male: female $=1.2: 1$. Nearly all patients had good performance status $(94.3 \%)$. Peripheral lymph nodes detected was the most common presenting 